\title{
The association between smoking and blood pressure in men: a cross-sectional study
}

\author{
Guoju Li ${ }^{6}$, Hailing Wang ${ }^{2}$, Ke Wang ${ }^{3}$, Wenrui Wang ${ }^{2}$, Fen Dong ${ }^{4}$, Yonggang Qian², Haiying Gong ${ }^{5}$, Chunxia Hui ${ }^{2}$, \\ Guodong $\mathrm{Xu}^{4}$, Yanlong Li ${ }^{1}$, Li Pan ${ }^{1}$, Biao Zhang ${ }^{1}$ and Guangliang Shan ${ }^{1 *}$
}

\begin{abstract}
Background: Cigarette smoking is a known risk factor for cardiovascular disease (CVD), but the association between smoking and blood pressure is unclear. Thus, the current study examined the association between cigarette smoking and blood pressure in men.

Methods: Systolic blood pressure (SBP), diastolic blood pressure (DBP), mean arterial pressure (MAP) and pulse pressure (PP) were examined using digital blood pressure measuring device, and smoking status was determined with China National Health Survey.

Results: The ANCOVA showed that the adjusted DBP and MAP were lower in current smokers versus nonsmokers and the adjusted SBP was lower in current smokers versus former smokers $(P<0.05)$. Additionally, the adjusted PP tend to be decreased steadily as the pack.years increased in current smokers. In a fully adjusted logistic regression model, former smokers had increased ORs $(95 \% \mathrm{Cl})$ of $1.48(1.01,2.18)$ of hypertension and current smokers had not increased ORs $(95 \% \mathrm{Cl})$ of $0.83(0.61,1.12)$, compared with never smokers.

Conclusions: The findings revealed that the adjusted blood pressure were lower in current smokers versus nonsmokers and former smokers. No significant dose-dependent effect of current smoking on blood pressure indices except PP was observed. Smoking cessation was significantly associated with an increased risk of hypertension. However, current smoking was not a risk factor of hypertension.
\end{abstract}

Keywords: Blood pressure, Hypertension, Smoking, Tobacco

\section{Background}

Hypertension, also known as high blood pressure, was defined as systolic blood pressure (SBP) of at least $140 \mathrm{mmHg}$, or diastolic blood pressure (DBP) of at least $90 \mathrm{mmHg}$, or self-reported diagnosis of hypertension. Hypertension is a major public health problem around the world. A cross-sectional study conducted in 17 countries and 142,042 adults showed that the prevalence of hypertension was $40.8 \%$ [1], and in China the prevalence of hypertension was $41.9 \%$ [2]. Hypertension was the leading risk factor for global disease burden and accounting for

\footnotetext{
* Correspondence: guangliang_shan@163.com

${ }^{1}$ Department of Epidemiology and Statistics, Institute of Basic Medical Sciences, Chinese Academy of Medical Sciences, School of Basic Medicine, Peking Union Medical College, Beijing, China

Full list of author information is available at the end of the article
}

9.4 million deaths in 2010 [3]. It contributes to the burden of stroke, heart disease and kidney failure. It is responsible for at least $51 \%$ of deaths due to stroke and $45 \%$ of deaths due to heart disease [4].

In 2015, the age-standardised prevalence of daily smoking was $25.5 \%$ for men and $5.4 \%$ for women worldwide, and in China the prevalence of daily smoking was $37.5 \%$ for men and $2.2 \%$ for women [5]. The WHO estimates that about $49.3 \%$ of men and about $2.0 \%$ of women aged 15 and over smoked in China [6]. Cigarette smoking is a considerable risk to public health, being responsible for nearly 6.3 million deaths and $6.3 \%$ of global DALYs worldwide [3]. It is a major risk factor for several diseases, including lung cancer [7], coronary heart disease [8], and stroke [9]. However, the relationship between smoking and blood pressure are not 
univocal, with some studies showing a positive [10, 11], and others an inverse association [12, 13]. Cavusoglu reported that smoking could cause direct endothelial damage, leading to endothelial dysfunction and impairment of endothelium dependent coronary vasodilation [14]. In addition, studies have concluded that smoking produces statistically significant changes in forearm haemodynamics affecting both small and large arteries [15], damage to the endothelium [16], and thought to be important in the pathophysiology of hypertension. The American Heart Association (AHA) blood pressure measurement recommendations pointed out that clinicbased measurements that predict vascular disease include SBP and DBP, as well as mean arterial pressure (MAP) and pulse pressure (PP) [17]. To our knowledge, there is no study of the relationship between smoking and blood pressure indices in China. In this study, we aimed to investigate the association between smoking and blood pressure in men in Inner Mongolia.

\section{Methods \\ Data}

The data was derived from the "China National Health Survey (CNHS)" study and collected in 2014. This is a cross-sectional study and designed to examine the relationship of cigarette smoking and blood pressure in men. A sample aged 20-80 years was selected using a multistage cluster sampling method, including Bayan Nur, Xilingol League, Ulanqab and Hohhot, which has been extensively described early [18].

Recruited participants include residents who had been living in Inner Mongolia for more than 1 year. Subjects were regarded as Mongolian or Han people if they and their parents were all Mongolian or Han ethnicity. Of the 1334 men aged $20-80$ years, we excluded 55 subjects who were not Mongolian or Han, 2 subjects aged less than 20 and 29 subjects with missing values on baseline characteristics. Ultimately, the study population consisted of 1248 subjects. When we study the association between smoking status and SBP, DBP, MAP and PP, 226 self-reported use of pharmacological medication for the hypertension that might affect blood pressure were excluded from the study.

All participants provided written informed consent. The study was approved by the Institutional Review Board of the Institute of Basic Medical Sciences, Chinese Academy of Medical Sciences.

\section{Health survey}

A self-reported questionnaire was used to obtain the demographic information, tobacco consumption status and history of diseases. The use of trained interviewers, and the qualified program managers checks on responses of participants improved the validity of the self- reported data. Indices of blood pressure, including SBP, DBP, MAP and PP, were measured in all eligible participants. The measurements were measured by trained medical staffs under the supervision the qualified program managers.

Subjects were divided into never smokers, former smokers and current smokers, on the basis of the amount of cigarette smoking and smoking habits in the questionnaire. Current cigarette smokers were defined as those people who smoked at least one cigarette per day and last for at least 6 months. Former smokers were defined as those people who had stopped smoking more than 6 months prior to the study. Smoking pack-years are calculated as the average number of packs smoked per day multiplied by the total number of years smoked during lifetime. Smokers were classified according to current smoking habits into four categories: 'light smokers (0.025-5 smoking pack.years),' 'medium smokers (5-14 smoking pack.years)' 'heavy smokers (14-26 smoking pack.years)', and 'extreme smokers (more than 26 smoking pack.years)'.

Drinking status was divided into three categories: never drinkers, light drinkers (consumption no more than $30 \mathrm{ml}$ of ethanol per day) and heavy drinkers (consumption more than $30 \mathrm{ml}$ of ethanol per day).

\section{Measurements}

Height was measured to nearest $0.1 \mathrm{~cm}$ using fixed stadiometer, whereas weight was measured with slandered weighing scale (BC-420, TANITA, Japan). Body mass index (BMI) was calculated as the subject's weight $(\mathrm{kg})$ divided by the height squared (metres). Participants were classified to lean or healthy, overweight, and obesity according to the World Health Organization criteria. Blood pressure was measured from sitting position using standardized procedure using digital blood pressure measuring device (Omron HEM-907, Japan). MAP was calculated as $(\mathrm{SBP}+2 \mathrm{DBP}) / 3$, while PP was calculated as SBP-DBP. Hypertension was defined as an average (calculated from 3 measurements) systolic blood pressure (SBP) $\geq 140 \mathrm{mmHg}$, or an average diastolic blood pressure (DBP) $\geq 90 \mathrm{mmHg}$, or self-reported diagnosis of hypertension.

\section{Statistical analysis}

The characteristics of the groups according to the smoking status were based on the Chi-square test or One-way analysis of variance for differences among frequencies and means, respectively. The bonferroni method was used for multiple comparisons. ANCOVA tests were used to compare SBP, DBP, MAP and PP among the smoking groups, while adjusting for age, BMI, alcohol drinking and ethnicity. Trend analysis of SBP, DBP, MAP and PP according to current smoking habits was performed using General linear model analysis, current 
smoking habits was an independent and continuous variable. We also examine the associations between smoking status and hypertension, multivariate logistic regression analysis, using a enter method, was performed to examine the associations. All $P$ values of less than .05 were considered to be statistically significant. All of the analyses were performed using SAS software version 9.2 (SAS Institute Inc., Cary, NC, USA).

\section{Results}

In the present study, a total of 1248 individuals were included in the analysis, the mean age was $46.21 \pm 14.00$ years. When we stratified by smoking status, there were $220(17.63 \%)$ former smokers, and 673(53.93\%) current smokers. As presented in Table 1, former smokers were older (Bonferroni, $P<0.0167$ ), shorter(Bonferroni, $P<0.0167$ ), and the mean BMI was higher (Bonferroni, $P<0.0167)$ when compared with nonsmokers and current smokers. There were significantly more heavy drinking current smokers compared with the never smoking category (Bonferroni, $P<0.0056$ ).

Table 2 shows SBP, DBP, MAP and PP in nonsmokers, former smokers and current smokers. After adjustment for age, BMI, alcohol drinking and ethnicity, ANCOVA comparisons showed no significant differences in blood pressure indices (all $P>0.05$ ), except DBP and $\operatorname{MAP}(P<0.05)$, in current smokers versus nonsmokers. In addition, when compared with former smokers, current smokers tended to have a lower SBP $(P<0.05)$.

Fig. 1. shows the unadjusted and adjusted means of blood pressure in current smokers. The unajusted SBP, DBP and MAP increased steadily as the pack.years increased in current smokers $\left(P_{\text {trend }}<0.05\right)$. The adjusted PP decreased as the pack.years increased in current smokers $\left(P_{\text {trend }}<0.05\right)$.
In Table 3, never smokers served as the control, the unadjusted OR $(95 \% \mathrm{CI})$ showed that the prevalence of hypertension was 2.36 (95\%CI:1.67-3.34) times higher in former smokers. The age-adjusted OR $(95 \% \mathrm{CI})$ and age, BMI-adjusted OR (95\% CI) both showed that the prevalence of hypertension was higher in former smokers $(\mathrm{OR}=1.77,95 \% \mathrm{CI}: 1.23-2.54 ; \mathrm{OR}=1.55$ 95\%CI:1.06-2.26, respectively). The multivariate models that considered age, BMI, alcohol drinking and ethnicity also showed similarly OR (95\% CI) of prevalence of hypertension for former smokers $(\mathrm{OR}=1.48,95 \% \mathrm{CI}: 1.01-2.18)$.

\section{Discussion}

This study examined the relationship between smoking and blood pressure in men. The findings revealed that the adjusted DBP and MAP were lower in current smokers versus nonsmokers. We also found that the adjusted SBP was lower in current smokers versus former smokers. Additionally, the unadjusted SBP, DBP and MAP increased steadily as the pack.years increased in current smokers, but only the adjusted PP tend to be decreased. The multivariate models indicated that former smoking was significantly associated with an increased risk of hypertension.

Alomari reported that smoking immediately increases DBP and MAP [19]. Studies indicated that elevated nicotine mediated an increase of sympathetic nervous system activities and released of epinephrine, norepinephrine and vasopressin hormones [20-22]. However, the long term effect is controversial. A cohort study conducted in Japanese men found that the adjusted mean of change in blood pressure of current smokers was lower than in nonsmokers [23]. Another cohort study conducted in Sweden women found that the adjusted mean of change

Table 1 Characteristics of the study population according to smoking status

\begin{tabular}{|c|c|c|c|c|}
\hline Variables & Never smokers $(n=355)$ & Former smokers $(n=220)$ & Current smokers $(n=673)$ & $P$ value \\
\hline Han,\% & 239(67.32) & 154(70.00) & 498(74.00) & 0.07 \\
\hline Age, years & $45.00 \pm 14.05$ & $55.62 \pm 12.56$ & $43.77 \pm 13.14$ & $<0.001$ \\
\hline Height, cm & $170.33 \pm 6.30$ & $169.01 \pm 6.17$ & $170.54 \pm 5.93$ & 0.005 \\
\hline Weight, kg & $73.74 \pm 12.65$ & $75.21 \pm 11.87$ & $73.00 \pm 12.57$ & 0.07 \\
\hline $\mathrm{BMI}, \mathrm{kg} / \mathrm{m}^{2}$ & $25.39 \pm 3.96$ & $26.29 \pm 3.55$ & $25.07 \pm 3.91$ & $<0.001$ \\
\hline \multicolumn{5}{|l|}{$\mathrm{BMI}, \%$} \\
\hline Lean or healthy & $174(49.01)$ & $76(34.55)$ & $330(49.03)$ & \multirow[t]{3}{*}{0.003} \\
\hline Overweight & 139(39.15) & $115(52.27)$ & $268(39.82)$ & \\
\hline Obesity & $42(11.83)$ & 29(13.18) & 75(11.14) & \\
\hline \multicolumn{5}{|l|}{ Alcohol Drinking, \% } \\
\hline Never & $98(27.61)$ & 43(19.55) & $109(16.20)$ & \multirow[t]{3}{*}{$<0.001$} \\
\hline Light & 173(48.73) & 107(48.64) & $328(48.74)$ & \\
\hline Heavy & $84(23.66)$ & $70(31.82)$ & 236(35.07) & \\
\hline
\end{tabular}


Table 2 Blood pressure indices of the study population according to smoking status

\begin{tabular}{llll}
\hline Variables & Never smokers $(n=303)$ & Former smokers $(n=145)$ & Current smokers $(n=574)$ \\
\hline Systolic blood pressure, $\mathrm{mmHg}$ & $125.81 \pm 13.13$ & $126.52 \pm 13.30$ & $124.11 \pm 14.41^{\mathrm{b}}$ \\
Diastolic blood pressure, $\mathrm{mmHg}$ & $79.65 \pm 9.77$ & $79.58 \pm 9.90$ & $78.35 \pm 10.73^{\mathrm{a}}$ \\
Pulse pressure, $\mathrm{mmHg}$ & $46.15 \pm 8.90$ & $46.94 \pm 9.02$ & $45.77 \pm 9.77$ \\
Mean arterial pressure, $\mathrm{mmHg}$ & $95.04 \pm 10.19$ & $95.22 \pm 10.33$ & $93.60 \pm 11.19^{\mathrm{a}}$ \\
\hline
\end{tabular}

Data are in mean \pm SD. ANCOVA tests were used to compare SBP, DBP, MAP and PP among the smoking groups, while adjusting for age, BMI, alcohol drinking and ethnicity

a: denotes statistical significance between Never smokers and current smokers

b: denotes statistical significance between former smokers and current smokers

in blood pressure of current smokers was higher than in nonsmokers [24].

Many early epidemiological studies have reported that there were no significant dose-effect relationships between smoking amount and SBP or DBP [25, 26]. A study in Japanese men showed that there were no relationships between smoking amount and SBP or DBP when lifestyle and other confounding factors were considered [25]. A meta-analysis of 23 population-based studies including a total of 141,317 individuals also found that there was no causal association between smoking heaviness in current smokers and SBP or DBP [26]. A recent study has shown that two SNPs located on chromosome 14 (rs11158609) and 17 (rs8078051) significantly associated with SBP including the genetic interaction with cigarette smoking [27]. A further study between the blood pressure and genetic susceptibility is urgently needed to clarify the observation.
We have not found any epidemiological study reporting the associations between smoking amount and PP or MAP in adults. The Irbid-TRY study conducted in male adolescent showed that smoking cigarettes predicted lower SBP, DBP, MAP and PP, even when confounding factors were added to the regression model [28]. Our study also found that the adjusted SBP was lower in current smokers versus former smokers. We also found that former smoking was a risk factor in prevalence of hypertension, but the current smoking was not associated with the prevalence of hypertension in all models. Some studies have conducted that acute blood pressure increase from tobacco smoking [29] and that blood pressure decreases 1-week after smoking cessation [30]. However, there is no consensus regarding the role of smoking in long-term blood pressure in generally healthy people and the effect of smoking cessation on blood pressure remains unclear with contradictory findings [10, 23, 31-33]. A recent meta-analysis including 62

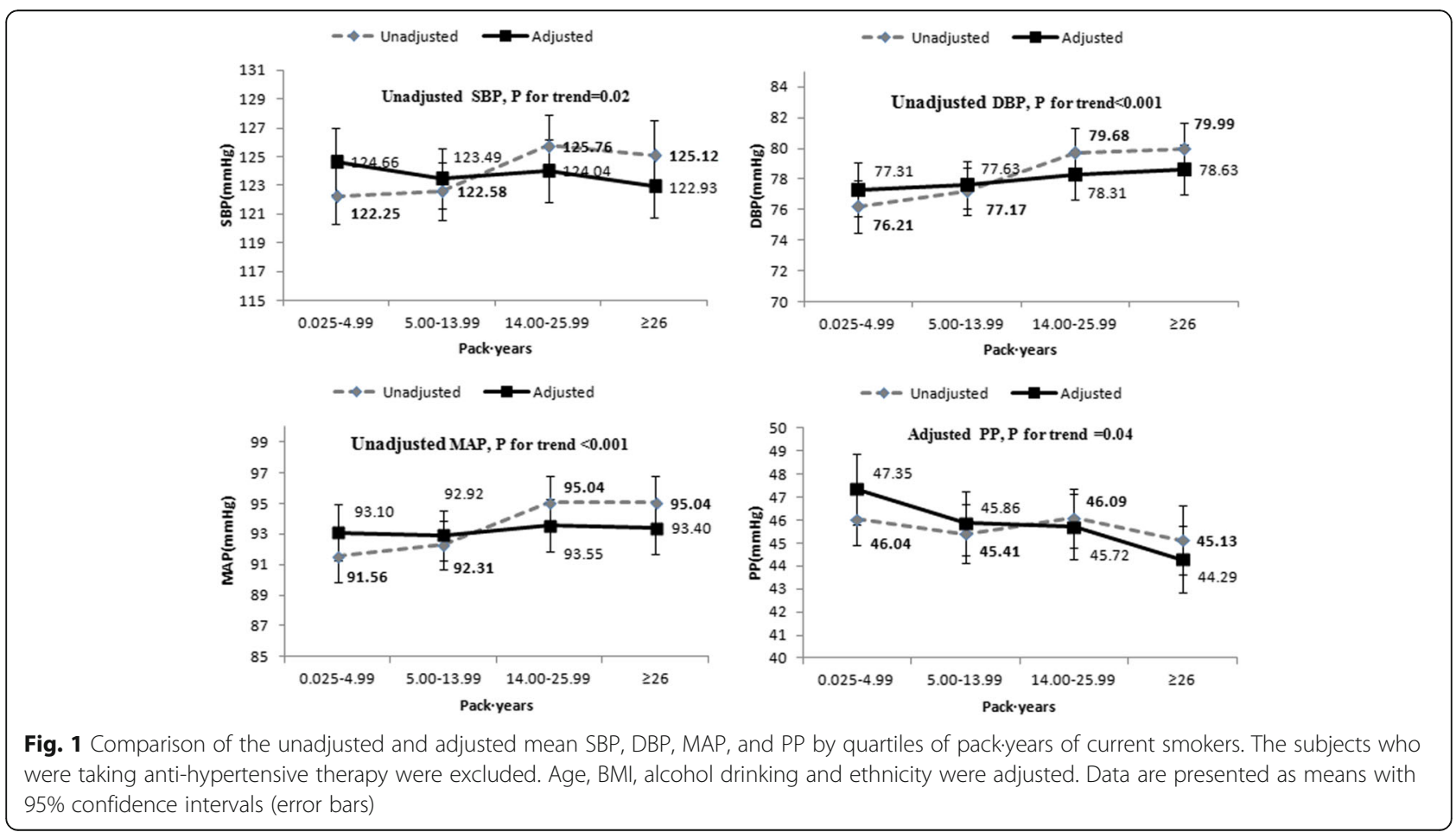


Table 3 Association between smoking status and hypertension by multivariate logistic regression models

\begin{tabular}{llll}
\hline Variables & Never smokers $(n=355)$ & Former smokers $(n=220)$ & Current smokers $(n=673)$ \\
\hline Total number of people with hypertension, $\%$ & $121(34.08)$ & $121(55.00)$ & $206(30.61)$ \\
Unadjusted $\mathrm{OR}(95 \% \mathrm{Cl})$ & $1.00(\mathrm{ref})$ & $2.36(1.67-3.34)$ & $0.85(0.65-1.12)$ \\
Age-adjusted $\mathrm{OR}(95 \% \mathrm{Cl})$ & $1.00(\mathrm{ref})$ & $1.77(1.23-2.54)$ & $0.86(0.65-1.14)$ \\
Age, BMl-adjusted $\mathrm{OR}(95 \% \mathrm{Cl})$ & $1.00(\mathrm{ref})$ & $1.55(1.06-2.26)$ & $0.88(0.66-1.19)$ \\
Multivariate-adjusted ${ }^{\mathrm{a}} \mathrm{OR}(95 \% \mathrm{Cl})$ & $1.00(\mathrm{ref})$ & $1.48(1.01-2.18)$ & $0.83(0.61-1.12)$ \\
\hline
\end{tabular}

${ }^{a}$ Adjusted for age, BMI, alcohol drinking and ethnicity

randomized controlled trials concluded that smoking cessation was associated with a mean weight gain of 4$5 \mathrm{Kg}$ after 1 year of abstinence [34]. Our data indicated that former smokers had a slightly higher mean BMI than current smokers and nonsmokers $(P<0.0167$ for bonferroni test). After a careful reanalysis the data, the adjusted ORs $(95 \% \mathrm{CI})$ of prevalence of hypertension in former smokers was $2.17(1.52,3.10)$ and this result was in accordance with our findings. We also tried to analyse the relationship between the date of hypertension diagnosed and smoking prohibiting time $(n=80)$, we found that $55 \%(44 / 80)$ of subjects suffer from hypertension after stop smoking. In addition, we found the prevalence of stroke and heart disease was higher in the former smokers than never smokers and current smokers $(17.73 \%$ vs. 7.61 and 7.88 , respectively).This may due to the high prevalence of hypertension in the former smokers. Smoking is a known risk factor of lung cancer, coronary heart disease and stroke, when subjects got this disease, they may stop smoking under the advice of doctors.

Strength of this study is that its sample is representative of the general population aged 20-80 of men. In addition, this is the first study which demonstrated the relationship between smoking and the four blood pressure indices among men in China. On the other hand, this study has limitations. This is a cross-sectional study and the data do not allow the final conclusions about causal relations. Therefore, cohort studies are needed to further understand the chronic effect of smoking on blood pressure. Furthermore, sample size was relatively small, and further studies need to examine the association between smoking and blood pressure in larger sample. In addition, BMI, age, alcohol consumption and ethnicity might be more useful. Likewise, residual confounding due to lifestyle factors cannot be excluded.

\section{Conclusions}

The current study revealed the relationship between smoking and blood pressure indices in China. The findings revealed that the adjusted blood pressure were lower in current smokers versus nonsmokers and former smokers. No significant dose-dependent effect of current smoking on blood pressure indices except PP was observed. Smoking cessation was significantly associated with an increased risk of hypertension.

\section{Abbreviations}

AHA: American Heart Association; BMI: Body mass index; DBP: Diastolic blood pressure; MAP: Mean arterial pressure; PP: Pulse pressure; SBP: Systolic blood pressure

\section{Acknowledgements}

This study was supported by the National Science and Technology Pillar Program during the Twelfth Five-Year Plan Period sponsored by the Ministry of Science and Technology of China (Grant No. 2012BAI37B02). We sincerely express our gratitude to all the staff of Inner Mongolian Autonomous Region Center for Disease Control and Prevention for support with the collection of demographic data.

\section{Funding}

The study was supported by the National Science and Technology Pillar Program during the Twelfth Five-Year Plan Period sponsored by the Ministry of Science and Technology of China (Grant No. 2012BAl37B02).

\section{Availability of data and materials}

Available with the research team.

\section{Authors' contributions}

GL participated in the data collection and drafted the manuscript. HW, WW, $H G, Y Q, C H, G X, Y L, B Z$ participated in the data collection. KW, FD, LP, GS participated in the design of the study and undertook statistical analyses. All authors approved the final manuscript.

\section{Ethics approval and consent to participate}

The study was approved by the Ethics Committee of the Institute of Basic Medical Sciences of the Chinese Academy of Medical Sciences (028-2013), and all participants written informed consent. The study was performed in accordance with approved national guidelines.

\section{Consent for publication}

All authors made significant contributions to the manuscript and all authors have read and approved the final version as well as agreed with the publishment on BMC Public Health.

\section{Competing interests}

The authors declared that they have no competing interests.

\section{Publisher's Note}

Springer Nature remains neutral with regard to jurisdictional claims in published maps and institutional affiliations.

\section{Author details}

${ }^{1}$ Department of Epidemiology and Statistics, Institute of Basic Medical Sciences, Chinese Academy of Medical Sciences, School of Basic Medicine, Peking Union Medical College, Beijing, China. ${ }^{2}$ Inner Mongolia Center for Disease Control and Prevention, Hohhot, China. ${ }^{3}$ National Office for Maternal and Child Health Surveillance of China, Department of Obstetrics, Key Laboratory of Birth Defects and Related Diseases of Women and Children (Sichuan University), Ministry of Education, West China Second University Hospital, Sichuan University, Chengdu, China. ${ }^{4}$ China-Japan Friendship 
Hospital, Beijing, China. ${ }^{5}$ Fangshan District Center for Disease Control and Prevention, Beijing, China. ${ }^{6}$ Qingdao Women and Children's Hospital,

Qingdao University, Qingdao, Shandong 266011, China.

Received: 5 November 2016 Accepted: 27 September 2017

Published online: 10 October 2017

\section{References}

1. Chow CK, Teo KK, Rangarajan S, Islam S, Gupta R, Avezum A, Bahonar A, Chifamba J, Dagenais G, Diaz R, et al. Prevalence, awareness, treatment, and control of hypertension in rural and urban communities in high-, middle-, and low-income countries. JAMA. 2013;310(9):959-68.

2. Li W, Gu H, Teo KK, Bo J, Wang Y, Yang J, Wang $X$, Zhang H, Sun Y, Jia X, et al. Hypertension prevalence, awareness, treatment, and control in 115 rural and urban communities involving 47000 people from China. J Hypertens. 2016;34(1):39-46.

3. Lim SS, Vos T, Flaxman AD, Danaei G, Shibuya K, Adair-Rohani H, Amann M, Anderson HR, Andrews KG, Aryee M, et al. A comparative risk assessment of burden of disease and injury attributable to 67 risk factors and risk factor clusters in 21 regions, 1990-2010: a systematic analysis for the Global Burden of Disease Study 2010. Lancet. 2012;380(9859):2224-60.

4. WHO. A Global Brief on Hypertension: Silent Killer, Global Public Health Crisis; World Health Day 2013. Geneva: WHO; 2013. p. 1-39.

5. Vasily V: Smoking prevalence and attributable disease burden in 195 countries and territories, 1990-2015: a systematic analysis from the Global Burden of Disease Study 2015. 2017.

6. Organization WH: WHO global report on trends in prevalence of tobacco smoking 2015. 2015.

7. Hong S, Mok Y, Jeon C, Jee SH, Samet JM. Tuberculosis, smoking and risk for lung cancer incidence and mortality. Int J Cancer. 2016;139(11):2447-55.

8. Tolstrup JS, Hvidtfeldt UA, Flachs EM, Spiegelman D, Heitmann BL, Balter K Goldbourt U, Hallmans G, Knekt P, Liu S, et al. Smoking and risk of coronary heart disease in younger, middle-aged, and older adults. Am J Public Health. 2014;104(1):96-102.

9. Peters SA, Huxley RR, Woodward M. Smoking as a risk factor for stroke in women compared with men: a systematic review and meta-analysis of 81 cohorts, including 3,980,359 individuals and 42,401 strokes. Stroke. 2013; 44(10):2821-8.

10. Halperin RO, Gaziano JM, Sesso HD. Smoking and the risk of incident hypertension in middle-aged and older men. Am J Hypertens. 2008;21 (2):148-52.

11. Bowman TS, Gaziano JM, Buring JE, Sesso HD. A prospective study of cigarette smoking and risk of incident hypertension in women. J Am Coll Cardiol. 2007;50(21):2085-92.

12. Thuy AB, Blizzard L, Schmidt MD, Luc PH, Granger RH, Dwyer T. The association between smoking and hypertension in a population-based sample of Vietnamese men. J Hypertens. 2010;28(2):245-50.

13. Li H, Tong W, Wang A, Lin Z, Zhang Y. Effects of cigarette smoking on blood pressure stratified by BMI in Mongolian population, China. Blood Press. 2010;19(2):92-7.

14. Cavusoglu Y, Timuralp B, Us T, Akgun Y, Kudaiberdieva G, Gorenek B, Unalir A, Goktekin O, Ata N. Cigarette smoking increases plasma concentrations of vascular cell adhesion molecule-1 in patients with coronary artery disease. Angiology. 2004;55(4):397-402.

15. Berlin I, Cournot A, Renout P, Duchier J, Safar M. Peripheral haemodynamic effects of smoking in habitual smokers. A methodological study. Eur J Clin Pharmacol. 1990;38(1):57-60.

16. Ambrose JA, Barua RS. The pathophysiology of cigarette smoking and cardiovascular disease: an update. J Am Coll Cardiol. 2004;43(10):1731-7.

17. Pickering TG, Hall JE, Appel L, Falkner BE, Graves J, Hill MN, Jones DW, Kurtz T, Sheps SG, Roccella EJ. Recommendations for blood pressure measurement in humans and experimental animals: part 1: blood pressure measurement in humans: a statement for professionals from the Subcommittee of Professional and Public Education of the American Heart Association Council on High Blood Pressure Research. Circulation. 2005;111(5):697-716.

18. Li G, Wang H, Wang K, Wang W, Dong F, Qian Y, Gong H, Xu G, Li Y, Pan L, et al. Prevalence, awareness, treatment, control and risk factors related to hypertension among urban adults in Inner Mongolia 2014: differences between Mongolian and Han populations. BMC Public Health. 2016;16:294.

19. Alomari MA, Khabour OF, Alzoubi KH, Shqair DM, Eissenberg T. Central and peripheral cardiovascular changes immediately after waterpipe smoking. Inhal Toxicol. 2014;26(10):579-87.
20. Cryer PE, Haymond MW, Santiago JV, Shah SD. Norepinephrine and epinephrine release and adrenergic mediation of smoking-associated hemodynamic and metabolic events. N Engl J Med. 1976;295(11):573-7.

21. Narkiewicz K, van de Borne PJ, Hausberg M, Cooley RL, Winniford MD, Davison DE, Somers VK. Cigarette smoking increases sympathetic outflow in humans. Circulation. 1998;98(6):528-34.

22. Waeber B, Schaller MD, Nussberger J, Bussien JP, Hofbauer KG, Brunner HR. Skin blood flow and cigarette smoking: the role of vasopressin. Clinical and experimental hypertension Part A, Theory and practice. 1984;6(10-11):2003-6.

23. Okubo Y, Suwazono Y, Kobayashi E, Nogawa K. An association between smoking habits and blood pressure in normotensive Japanese men: a 5year follow-up study. Drug Alcohol Depend. 2004;73(2):167-74.

24. Janzon E, Hedblad B, Berglund G, Engstrom G. Changes in blood pressure and body weight following smoking cessation in women. J Intern Med. 2004:255(2):266-72.

25. Okubo Y, Miyamoto T, Suwazono Y, Kobayashi E, Nogawa K. An association between smoking habits and blood pressure in normotensive Japanese men. J Hum Hypertens. 2002;16(2):91-6.

26. Linneberg A, Jacobsen RK, Skaaby T, Taylor AE, Fluharty ME, Jeppesen JL, Bjorngaard JH, Asvold BO, Gabrielsen ME, Campbell A, et al. Effect of Smoking on Blood Pressure and Resting Heart Rate: A Mendelian Randomization Meta-Analysis in the CARTA Consortium. Circ Cardiovasc Genet. 2015;8(6):832-41.

27. Taylor JY, Schwander K, Kardia SL, Arnett D, Liang J, Hunt SC, Rao DC, Sun YV. A Genome-wide study of blood pressure in African Americans accounting for gene-smoking interaction. Sci Rep. 2016;6:18812.

28. Alomari MA, Al-Sheyab NA. Cigarette smoking lowers blood pressure in adolescents: the Irbid-TRY. Inhal Toxicol. 2016;28(3):140-4.

29. Najem B, Houssiere A, Pathak A, Janssen C, Lemogoum D, Xhaet O, Cuylits $\mathrm{N}$, van de Borne P. Acute cardiovascular and sympathetic effects of nicotine replacement therapy. Hypertension. 2006;47(6):1162-7.

30. Minami J, Ishimitsu T, Matsuoka H. Effects of smoking cessation on blood pressure and heart rate variability in habitual smokers. Hypertension. 1999; 33(1 Pt 2):586-90.

31. D'Elia L, De Palma D, Rossi G, Strazzullo V, Russo O, lacone R, Fazio V, Strazzullo P, Galletti F. Not smoking is associated with lower risk of hypertension: results of the Olivetti Heart Study. Eur J Pub Health. 2014; 24(2):226-30.

32. Patel K, Schlundt D, Larson C, Wang H, Brown A, Hargreaves M. Chronic illness and smoking cessation. Nicotine Tob Res. 2009;11(8):933-9.

33. John U, Meyer C, Hanke M, Volzke H, Schumann A. Smoking status, obesity and hypertension in a general population sample: a cross-sectional study. QJM. 2006;99(6):407-15.

34. Aubin HJ, Farley A, Lycett D, Lahmek P, Aveyard P. Weight gain in smokers after quitting cigarettes: meta-analysis. BMJ. 2012;345:e4439.

\section{Submit your next manuscript to BioMed Central and we will help you at every step:}

- We accept pre-submission inquiries

- Our selector tool helps you to find the most relevant journal

- We provide round the clock customer support

- Convenient online submission

- Thorough peer review

- Inclusion in PubMed and all major indexing services

- Maximum visibility for your research

Submit your manuscript at www.biomedcentral.com/submit
) Biomed Central 